\title{
Blood Analysis of Laboratory Macaca mulatta Used for Neuroscience Research: Investigation of Long-Term and Cumulative Effects of Implants, Fluid Control, and Laboratory Procedures
}

\author{
DDetlef Wegener, ${ }^{1}$ Dan Qi Priscilla Oh (胡箪棋), ${ }^{1}$ Herbert Lukaß, ${ }^{2}$ Michael Böer, ${ }^{3}$ and Andreas K. Kreiter ${ }^{1}$
}

\author{
https://doi.org/10.1523/ENEURO.0284-21.2021
}

${ }^{1}$ Brain Research Institute, Center for Cognitive Science, University of Bremen, 28334 Bremen, Germany, ${ }^{2}$ Department of Biology, University of Bremen, 28334 Bremen, Germany, and ${ }^{3}$ Institute of Terrestrial and Aquatic Wildlife Research, University of Veterinary Medicine, 30559 Hannover, Germany

\begin{abstract}
The nonhuman primate (NHP) constitutes an extraordinarily important model in neuroscience research for understanding the neuronal underpinnings of perceptual, motor, cognitive, and executive functions of the primate brain, and to study the physiological causes, effects, and potential treatments of brain disorders. Because of their cognitive capabilities, NHPs receive special attention in animal welfare regulations around the world, and their well-being is a benchmark for the evaluation, monitoring, and refinement of experimental procedures. As a consequence, many typical neuroscientific procedures are considered only mildly severe by animal welfare boards. There is, however, an ongoing debate about possible long-term and cumulative effects. Because of a lack of longitudinal data, it is unclear whether mildly severe procedures may cause more significant harm on the long-term, and to what extent they may impact animal well-being and healthiness over time. We here make use of a database of blood samples drawn over a period of 15 years from 39 rhesus monkeys (Macaca mulatta) to address the issue of long-term, cumulative effects of neuroscientific procedures. A careful analysis of indicative primate blood markers for chronic inflammation, hydration status, and stress levels, their comparison to baseline values from both the same animals and the literature, and evaluation of additional hematologic, physiological, and behavioral parameters did not provide support for the notion of long-term, cumulative effects on the monkeys' healthiness and well-being. The results may serve the community as a reference for the severity assessment of neuroscientific experiments involving NHPs.
\end{abstract}

Key words: cumulative effects; long-term effects; neuroscientific procedures; non-human primate; severity

\section{Significance Statement}

Whether and to what extent standard nonhuman primate (NHP) neuroscientific procedures would cause cumulative harm, either because of combining different methods or over time, is an important concern addressed by both legislative guidelines and local authorities. We have analyzed a database of blood samples drawn over a period of 15 years with regard to cranial implants, fluid protocols, and laboratory procedures, supplemented by veterinarian records on physiological and behavioral attributes. A thorough investigation of the data and their comparison to baseline values from the same animals, taken before start of laboratory work, does not support the notion of cumulative effects. The results show that monkeys may well adapt to laboratory procedures and successfully manage their health and well-being as during baseline periods.

Received July 1, 2021; accepted September 2, 2021; First published September 23, 2021.

The authors declare no competing financial interests.
Author contributions: D.W. and D.Q.P.O. designed research; D.W., D.Q.P.O., H.L., M.B., and A.K.K. performed research; D.W. and D.Q.P.O. analyzed data; D.W. wrote the paper. 


\section{Introduction}

Because of their genomic and physiological similarity to humans, non-human primates (NHPs) constitute an indispensable laboratory model for various fields of biomedical research, including brain research, neurology, hematology, and immunology (Anderson, 2008; Gardner and Luciw, 2008; Evans and Silvestri, 2013; Roelfsema and Treue, 2014; Verdier et al., 2015), with research on SARS-CoV2 (Chandrashekar et al., 2020; Deng et al., 2020; Munster et al., 2020) and preclinical testing of vaccine candidates (Corbett et al., 2020; Mercado et al., 2020; van Doremalen et al., 2020; Vogel et al., 2021) to fight the COVID-19 pandemic as recent examples. In systems neuroscience, NHP research led to the establishment of theories on complex neuronal interactions required to understand and eventually treat brain diseases and mental disorders (Uhlhaas and Singer, 2006; Siegel et al., 2012; Fries, 2015; Kreiter, 2020) and to the discovery of the mirror neuron system (Rizzolatti and Craighero, 2004), to name two key areas of research. Macaque monkeys represent the long-standing model for understanding the human brain in health and disease, because of the degree of similarity in brain anatomy and connectivity (Orban et al., 2004; Rauschecker and Scott, 2009; Petrides et al., 2012; Thiebaut de Schotten et al., 2012), motor actions (Munoz and Everling, 2004; Rizzolatti and Rozzi, 2016; Castiello and Dadda, 2019), and perceptual, cognitive, and social abilities (Deaner and Platt, 2003; Kastner et al., 2008; Hosokawa and Watanabe, 2012; Rajalingham et al., 2015; Hanks and Summerfield, 2017; Gray and Barnes, 2019; Roberts and Clarke, 2019), recently supplemented by the common marmoset (Callithrix jacchus) to facilitate genetic engineering studies (Tokuno et al., 2015).

Because of the ethical constrains arising from their cognitive and behavioral capabilities, the work with NHPs requires particularly careful behavioral and laboratory management protocols to ensure their welfare in husbandry and experiment. Besides other measures, this includes regular acquisition of hematologic and biochemical blood parameters as important indicators of an individual's health and well-being (Bernacky et al., 2002). In NHP systems neuroscience research, regular blood sampling may help to identify issues arising from typical procedures, as, e.g., implantation of a headpost and recording chamber (or other equipment used for signal acquisition), protocols for controlled water or food supply, transfer to and stay in laboratory space, and long periods of data acquisition (both daily and absolute), all of

This work was supported by the German Research Foundation Grant WE 5469/3-1.

Acknowledgements: We thank all current and previous lab members for their support and engagement in monkey welfare. We particularly thank Ramazani Hakizimani and Katrin Thoss for animal care and running the husbandry and Katja Taylor for careful keeping records of samples.

Correspondence should be addressed to Detlef Wegener at dwegener@ uni-bremen.de.

https://doi.org/10.1523/ENEURO.0284-21.2021

Copyright (C) 2021 Wegener et al.

This is an open-access article distributed under the terms of the Creative Commons Attribution 4.0 International license, which permits unrestricted use, distribution and reproduction in any medium provided that the original work is properly attributed. which may exerts an influence on physiological parameters and shows up in hemograms. Careful scientific analysis of such procedures is considered a constant task in the community, and many refinements have been implemented because of the results of systematic investigations (for expert group review, see Prescott et al., 2010). There is, however, a lack of longitudinal studies to clarify whether procedures indicating no or mild severity on the short term may exert cumulative and more severe effects on the long-term. Accordingly, the EU Directive 2010/63 on the use of animals in research particularly emphasizes the "lifetime experience" of laboratory animals and requests assessment of possible cumulative effects related to specific scientific procedures for assignment of severity categories.

We here make use of a blood sample database acquired over a period of 15 years. We address the questions whether and to what extent typical neuroscientific procedures may cause hematologic deviations from baseline, with special emphasis on cumulative, long-term effects. All samples were drawn under largely identical conditions of husbandry and laboratory procedures, and were analyzed by the same biomedical lab to minimize hidden variance. We address whether there would be firstly, chronic inflammatory responses because of cranial implants, secondly, altered kidney values because of controlled fluid supply, and thirdly, stress responses because of laboratory procedures during training and recording periods. All data are compared with baseline values obtained from the same animals before implantation and start of laboratory procedures, and to published reference values. Blood parameter analysis is supplemented by an evaluation of $>2000$ score sheets on outer appearance and behavior of the monkeys, assessed by an external veterinarian, to address possible changes in general health conditions over the course of time.

The results do not provide statistical evidence of cumulative effects arising from long-term presence of cranial implants, repeated periods of fluid control, or continuing exposure to laboratory procedures, or from the combination of these methods. Given adherence to state-of-theart husbandry and laboratory methods, they suggest that monkeys may well adapt to experimental settings and effectively manage their health and well-being.

\section{Materials and Methods}

\section{Animals and husbandry conditions}

The database consisted of a total of $N=248$ blood samples drawn from 39 male rhesus monkeys over a period of 15 years (2006-2020). All monkeys were bred for scientific purposes and were obtained from the German Primate Center. Monkeys were aged between 2 and 18 years at the time of sampling. They were kept in groups of two or four animals and were housed in large compartments providing indoor and outdoor areas, swings, ropes, climbing opportunities and a manifold of environmental enrichments, hiding areas and sufficient space for vertical flights. Some elderly animals were housed singly in indoor compartments with visual and 
auditory contact to other animals. Health and well-being were daily monitored by animal caretakers and scientific personnel and by regular veterinary visits (H.L.). All behavioral training on husbandry and laboratory requirements was strictly based on positive reinforcement, including training to enter primate chairs. No collars were used. Husbandry training was performed using fruits as reinforcer, and laboratory training used juice and/or water as reinforcer, depending on the individual monkey's preferences. Husbandry conditions and procedures, veterinary, laboratory, surgical, and experimental procedures followed the Directive 2010/63, issued by the European Parliament (European Parliament, 2010), and the Regulation for the Welfare of Experimental Animals, issued by the Federal Government of Germany, and were approved and regularly controlled by the local authorities.

\section{Cranial implants}

Implants in the current study consisted of caps made from bone cement and dental acrylic, as described in detail by Gardiner and Toth (1999). Different from the original protocol, cranial implants were implanted in a bipartite procedure, which allowed for a significant refinement over the traditional protocol. In a first surgery, only a thin layer of bone cement (anchored by medical screws) was laid out and the untrimmed skin was then placed in its original position, covering the cap, and closed by subcutaneous, interrupted sutures. A small opening $(\sim 1 \mathrm{~cm}$ in diameter) remained at, or close to, the center of the new implant, typically at the intersection of a Y-cut to open the skin. Because the skin will not attach to the implant, it will slowly retract and eventually insert at the skull very close to the margins of the cap during the next four weeks, approximately. The main refinement is that, before retraction is completed, implant margins are covered by skin tissue and receive full immune protection. This minimizes the risk of infections, prevents undue growth of granulation tissue, and, as a consequence, strongly supports a firm attachment of the skin exactly at the margin of the cap. The typical result is a lasting condition (usually several years) during which routine care required for the cap is reduced to a minimum. After the skin firmly attached to the skull, headholder, connectors and recording chambers were mounted/implanted in a second procedure.

\section{Data acquisition}

Blood samples in the database include blood drawn for yearly routine check, blood drawn when a potential health issue was raised, and blood drawn when an animal underwent surgery. All blood samples were indexed according to the reason of sampling (routine/health issues), status at the time of blood draw (awake/anesthetized), presence of a cranial implant (non-implanted/implanted), and experimental condition (lab/non-lab periods). Samples taken during non-lab periods were further indexed as either drawn shortly (3-10 d) after a lab period or drawn at later times $(>10 \mathrm{~d})$. For each sample, the database also held information about the dates of sample draw, monkey birth, and implantation surgery. Combination of indexes and consideration of time information allowed to differentiate suitable subsets of samples to address each specific question in this study.

\section{Sampling and anesthesia}

Blood samples were drawn from both awake and anesthetized animals. In awake procedures, monkeys entered a horizontal primate chair, in which they sat in a Sphinxlike position and the sample was drawn from its leg by opening the rear side of the chair. If an animal was not trained on the procedure at the time of sampling, it was lightly sedated with a low amount of ketamine/medetomidine. In the event of a surgery, monkeys were given ad libitum access to water for at least $48 \mathrm{~h}$. Water bottles were removed either the evening before the surgery (older samples) or about $2 \mathrm{~h}$ before surgery. Blood samples were taken in the first 60 min of the surgery. Initial anesthesia was typically performed using a mix of ketamine (4$8 \mathrm{mg} / \mathrm{kg}$ body weight) and medetomidine $(0.04 \mathrm{mg} / \mathrm{kg}$ body weight), supplemented with a low dose of isoflurane $(<0.5 \%)$. All blood samples in the database were taken from veins. Only samples from non-sedated animals were indexed as "awake." All other samples were indexed as "anesthetized."

\section{Fluid protocol during baseline, laboratory, and non-labora- tory periods}

Based on their indexing, all blood samples in the database were assigned to either baseline, laboratory, or nonlaboratory time periods. The baseline period is comprising all samples taken before implantation of the cranial cap and start of laboratory training. The laboratory period is comprising all samples drawn after implantation of the cranial cap, during periods of regular training or recording sessions. During these periods, monkeys receive water or fruit juice as a feedback reward and reinforcer for performing the laboratory task, usually a visual discrimination task (Wegener et al., 2004; Grothe et al., 2012; Schledde et al., 2017; Fischer and Wegener, 2018). On non-working days (e.g., during the baseline period or at the weekend during laboratory periods), monkeys receive fruits and liquids in generous amounts (i.e., fully satisfying their physiological needs and allowing to compensate any possible deficit from laboratory periods). Fruits and fluids were available throughout the day, or were given once or twice for several hours, depending on the monkey's individual protocol and the laboratory schedule of its group. Primate food pellets and seeds were available at all times. In the remainder of the paper, we refer to this schedule as "non-restricted." Non-laboratory periods are defined as periods following at least $3 \mathrm{~d}$ of non-restricted food and liquid supply after a training or experimental block; body weight was taken regularly during baseline and non-laboratory periods and every working day during laboratory periods.

\section{Other behavioral and physiological data}

All monkeys were regularly assessed by an external veterinarian with long-term, laboratory and non-laboratory NHP experience, typically without preceding announcement of his visit. Monkeys were scored for 11 attributes of 
Table 1: Scoring attributes and criteria

\begin{tabular}{|c|c|c|c|c|}
\hline Attribute & - & + & ++ & +++ \\
\hline Coat & Smooth, shiny & Rough, duff, protruding & Like + with gluing & Like ++ with loss of space \\
\hline Nutritional status & Good & Moderate & Skinny, fat & Atrophy, obese \\
\hline Mucosal membrane & Pale, pinkish red & Red & Washed out & Pale, cyanotic, yellow \\
\hline Behavior at rest & Relaxed & Tense & Trembling & Nervous, anxious \\
\hline Solitary behavior & Inconspicuous & $\begin{array}{l}\text { Unphysiological repetitions/ } \\
\text { apathy }\end{array}$ & Stereotypical & Ethopathological \\
\hline Social behavior & Cheerful, active & Passive, inhibited & \multicolumn{2}{|c|}{$\begin{array}{c}\text { Permanently threatened Permanently aggressive/ } \\
\text { defensive }\end{array}$} \\
\hline $\begin{array}{l}\text { Behavior in presence of } \\
\text { observer }\end{array}$ & Attentive & Indifferent & Angry, aggressive & $\begin{array}{l}\text { Attempt to escape/massive } \\
\text { attack }\end{array}$ \\
\hline
\end{tabular}

- equaled 0 SPs;,+++ , and +++ equaled 1, 2, and 3 SPs, respectively. A total of 4 SPs indicated slightly disturbed healthiness.

outer appearance and behavior. Note that on individual visits, one or more attributes were occasionally not scored because the monkey was engaged in a laboratory session, was not approaching close enough, or because of other reasons. Per assessed attribute, zero to three score points (SPs) were given (see Table 1 for scoring criteria). A total of four SP indicated the lower bound of overall "slightly disturbed" healthiness (i.e., mild severity). To assess individual monkeys, we calculated the ratio-tomild as $r$ tm $=\sum_{S P} / 4$, with $r t m=1$ indicating the transition from "no complaint" to "mild severity." Analysis of scores was performed (1) for individual monkeys, (2) for individual attributes, and (3) as function of time from date of implantation.

\section{Data analysis}

All blood probes were sent to the same independent, commercial biomedical laboratory for cell counts, differential, and electrophoresis and were assessed by a veterinarian of the laboratory before dispatch. All blood values were transferred to Excel spread sheets on postal or Email arrival. Manually completed score sheets were also transferred to Excel spread sheets. Data analysis was performed by custom-written scripts in MATLAB 2020a (The MathWorks), using samples drawn for routine health checks but excluding samples drawn for veterinary purposes. Statistical testing was performed using functions from MATLAB's Statistics and Machine Leaning Toolbox. False discovery rate (FDR) was calculated using the Benjamini and Yekutieli (2005) procedure (i.e., with no assumption on dependency structures), as provided in Groppe D (2021); fdr_bh (https://www.mathworks.com/ matlabcentral/fileexchange/27418-fdr_bh), MATLAB Central File Exchange, retrieved May 21, 2021.

\section{Statistics}

Significance is reported at $p<0.05$. With the exception of $r$ tm over time, all other analyses were performed using non-parametric tests. If applicable, post hoc analysis was performed using Tukey's HSD criterion. Ratio-to-mild rtm over time was tested by weighted regression, relying on $t$ statistics, and weights were chosen by the number of data available per bin. For testing effects over the entirety of blood values, false positives were controlled by setting the FDR criterion to $\alpha=0.1$. Literature values for comparison were obtained from Stanley and Cramer (1968), Rosenblum and Coulston (1981), Kessler and Rawlins (1983), Bennett et al. (1992), Fernie et al. (1994), Buchl and Howard (1997), Hom et al. (1999), Smucny et al. (2001), Andrade et al. (2004), Chen et al. (2009), Didier et al. (2012), Koo et al. (2019), and Yu et al. (2019). If a given paper reported blood values separately for male and female animals, we only considered males. If a paper reported blood values separately for different age groups, we excluded values from outside the range of our own cohort (2-18 years). If applicable, means and SDs of literature values were weighted by the number of samples in each age group. Likewise, combined statistics across literature values were weighted by sample size $N$ per study.

\section{Results}

\section{Database}

A total of 248 blood samples was drawn from 39 male rhesus monkeys. For each sample, the database included indexes on several criteria to characterize the reason for sampling, the presence of a cranial implant, the overall experimental conditions of the monkey delivering the sample (laboratory and non-laboratory periods), and anesthesia (see Materials and Methods). For each sample, the database also provided information about the time the sample was taken, the age of the monkey at the time of sampling, and, if applicable, the time of implantation and start of laboratory procedures of that individual. Combination of indexes and consideration of timing information allowed to differentiate suitable subsets of data for the different research 
A

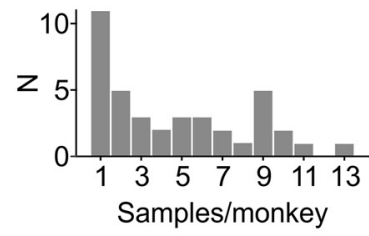

F

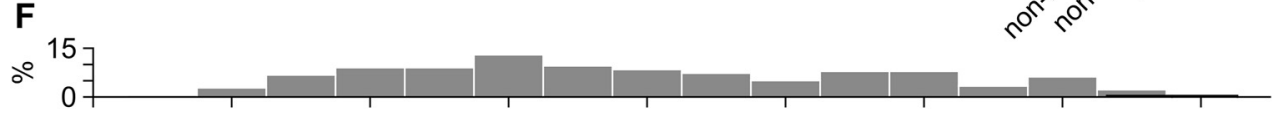

B

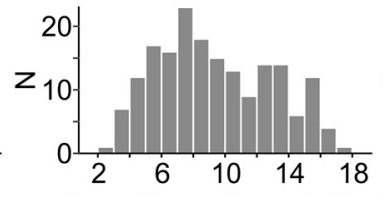

Age at time of sample [yrs]
C

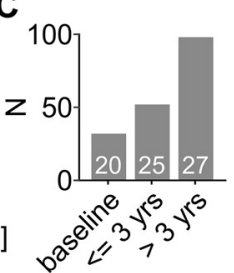

D

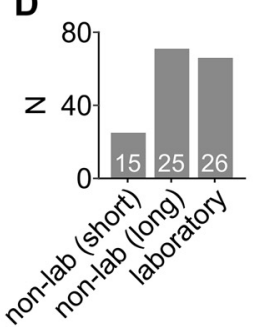

E

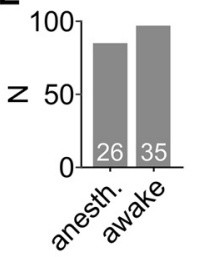

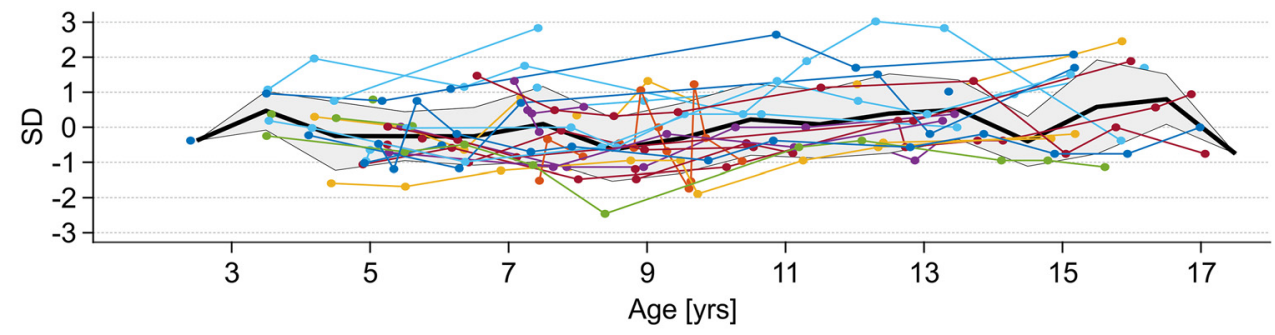

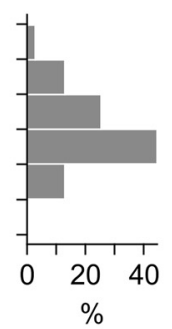

G

H

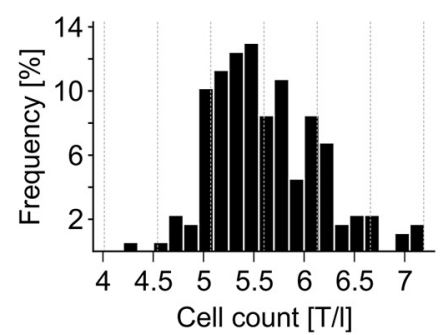

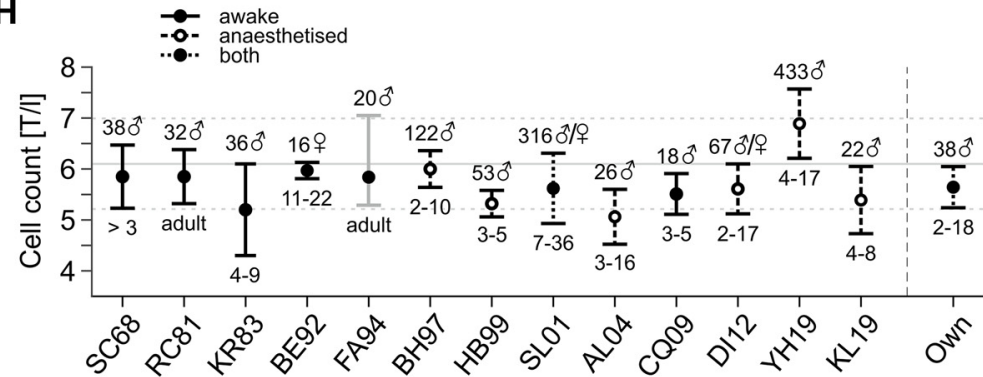

Figure 1. Database overview. A, Number of monkeys providing between 1 and 13 individual samples. $\boldsymbol{B}$, Number of samples obtained at different age. $\boldsymbol{C}$, Number of samples from monkeys without cranial implant and before start of laboratory procedures (baseline), during first three years after implantation ( $\leq 3$ years), and at later times ( $>3$ years). $\boldsymbol{D}$, Number of samples taken during laboratory and non-laboratory periods. Non-laboratory periods are periods in-between blocks of laboratory work; "Non-lab short" indicates samples taken after 3-10 d of free access to fluid and food; "Non-lab long" indicates samples drawn after $>10 \mathrm{~d}$ of free access. $\boldsymbol{E}$, Number of samples from anesthetized and awake monkeys. White numbers in $\boldsymbol{C}-\boldsymbol{E}$ indicate the number of individual monkeys contributing to the data. $\boldsymbol{F}$, Statistical distribution of single red blood cell samples as function of monkey age, estimated over entire database. Colored lines correspond to samples from individual animals. Bold black line indicates mean over all monkeys per age. Gray-shaded area indicates 1 SD per age. Horizontal histogram indicates percentage of samples per age, vertical histogram indicates percentage of samples in terms of SD. G, Distribution of red blood cell counts over all samples. T/l: $10^{12}$ cells/l. $\boldsymbol{H}$, Comparison of red blood cell counts to corresponding reports from the literature. Labeling of $x$-axis (SC68, ..., KL19) refers to Stanley and Cramer (1968), Rosenblum and Coulston (1981), Kessler and Rawlins (1983), Bennett et al. (1992), Fernie et al. (1994), Buchl and Howard (1997), Hom et al. (1999), Smucny et al. (2001), Andrade et al. (2004), Chen et al. (2009), Didier et al. (2012), Koo et al. (2019), and Yu et al. (2019), in that order. "Own" refers to data from present study, as shown in G. Signs on top of error bars indicate number and gender of animals, signs below error bars indicate age. Error bars indicate SD, with the exception of FA94, which represent data range (indicated by gray color of error bar).

questions to address. Indexes were used to identify the number of samples available for a given blood parameter or criterion as well as to identify the number of monkeys delivering these samples, and they underly all grouping of data in the remainder of the paper. An overview of the grouping will be provided in the following and the grouping will clearly be explained for each of the different analyses we perform.

Of all samples, $N=66(26.6 \%)$ were drawn because of veterinary purposes, e.g., as part of postoperative care. These samples were excluded from analysis. All other samples $(N=182)$ were drawn for reasons of routine health check. Individual monkeys provided between 1 and 14 samples (Fig. 1A), and they were aged between 2 and 17 years at the time of sampling (Fig. 1B). A total of 32 samples from 20 animals were drawn before cranial implantation and start of laboratory procedures. These served as a baseline condition for various analyses; 52 samples from 25 individual monkeys were drawn during the first three years after implantation and start of laboratory procedures, and 98 samples from 27 monkeys were drawn at later times (Fig. 1C). Likewise, 66 samples from 26 monkeys were drawn during times the monkeys were currently engaged in laboratory procedures with limited access to fluid and fruits, 25 samples from 15 monkeys were drawn during times after or in-between blocks of 
laboratory work, after 3-10 d of free access to food and fluid, and 71 samples from 25 monkeys were drawn after longer non-laboratory periods (Fig. 1D). Finally, 86 samples from 26 animals were drawn during anesthesia, usually shortly after induction, and 96 samples from 35 monkeys were drawn from awake individuals (Fig. 1E). Anesthesia did not affect blood parameters in our database, as tested on all samples drawn before cranial implantation and start of laboratory (Kruskal-Wallis tests on 45 blood parameters, $p$ values adjusted by FDR set to $\alpha=$ $10 \%$, all $p>0.11$ )

An illustrative example of the database is shown for red blood cells (Fig. 1F). The database delivered a total of $N=177$ routinely drawn red blood cell counts from 38 individual monkeys. $\sim 70.1 \%, 96.1 \%$, and $99.4 \%$ of all samples were within 1,2 , and 3 SDs of the distribution, respectively, closely matching normal distribution, and $87.6 \%$ were taken from animals between 4 and 15 years of age. The mean red blood cell count was $5.6 \pm 0.53 \times$ $10^{12}$ units per liter (T/l; Fig. 1G). Comparison to the literature (see Materials and Methods) reveals good correspondence with the majority of published baseline values; yet it also reveals a good degree of variability of this rather basic hematologic parameter across studies, co-existing with differences in gender, age, sample size, state of anesthesia, and possibly other, hidden sources of variance (Fig. 1H). This introduces some uncertainty for the interpretation of blood values, particularly if they may be influenced by the specific husbandry and experimental conditions, and underlines the importance of a baseline reference drawn under basically identical overall conditions, to reduce variance across samples to some minimum. For the following analyses, therefore, possible long-term health effects because of the presence of cranial implants, controlled fluid supply, and potential stress arising from laboratory work were compared statistically to baseline values obtained from our own database, represented by samples from non-implanted animals before start of laboratory procedures (compare Fig. 1C, left bar). Literature values will be shown as complementary information.

\section{Effect of cranial implants}

Because of various methodological reasons, a typical neuroscience experiment with awake behaving monkeys requires one or several permanent cranial implants (headpost, recording chamber, electrode connectors, or the like). Implants, materials, and surgical procedures are subject to continuous refinement (Adams et al., 2007, 2011; Galashan et al., 2011; McAndrew et al., 2012; Lanz et al., 2013; Johnston et al., 2016; Chen et al., 2017; Overton et al., 2017), yet the presence of an implant may increase the risk of bacterial or fungal infection at the site of implantation (Gardiner and Toth, 1999; Johnston et al., 2016). We were, therefore, asking whether blood samples drawn from animals with cranial implants would provide evidence for chronic inflammatory responses, both on the short and long term, as compared with a baseline condition, consisting of samples routinely drawn before implantation and start of laboratory procedures.
For 11 animals, the database provided both baseline samples and samples drawn between 6 and 18 months after implantation. These allowed for a paired analysis to ask whether, across monkeys, there is evidence for a consistent increase in $\gamma$ globulin levels and leukocyte numbers, both being indicators of acute and chronic infections (Martin and Leibovich, 2005; Schroeder and Cavacini, 2010; Theil et al., 2021). We found that values after implantation were slightly higher than before implantation, yet neither for $\gamma$ globulin nor leukocytes did this increase reach statistical significance (Wilcoxon signedrank test, $p=[0.1750 .153], N=[1111]$ for $\gamma$ globulins and leukocytes, respectively; Fig. $2 A$ ). The number of leukocytes was well in the range of published values (all acquired from non-implanted animals), both before and after implantation (Fig. 2A, right panel). The level of $\gamma$ globulins could not be directly compared with the literature, because published values either do not consider globulins at all (Stanley and Cramer, 1968; Rosenblum and Coulston, 1981; Bennett et al., 1992; Andrade et al., 2004; Koo et al., 2019), consider total globulin (Kessler and Rawlins, 1983; Fernie et al., 1994; Buchl and Howard, 1997; Hom et al., 1999; Smucny et al., 2001; Chen et al., 2009; Didier et al., 2012; Yu et al., 2019), or report specific types of immunoglobulins (Yu et al., 2019), which consist mainly but not exclusively of $\lg G$ in the electrophoretic $\gamma$ spectrum. Among leukocytes, we also tested the differential cell counts before and after implantation, but did not find any significant deviation (Wilcoxon signed-rank tests, all $p>0.1$, all $N=11$ ), all white blood cells were well in the range of published values (Fig. $2 B$ ).

If not evident on the short-term, chronic infections because of the presence of a cranial implant may build up on longer time scales, over the course of several years. Per year after implantation, the database provided between minimally five and up to 23 routinely drawn samples over a period of 11 years (total $N$ : leukocytes: 124, $\gamma$ globulin: 147). However, apart from small, year-wise fluctuations there was no obvious pattern to suggest any longterm changes in blood levels of leukocytes and $\gamma$ globulin (Fig. 2C). Statistical analysis with the main factor "year after implantation" indicated no significant differences between $\gamma$ globulin levels (Kruskal-Wallis test, $\chi_{(11,123)}^{2}=11.89, p=$ 0.37 ), and no value was different from baseline (all $p>$ $0.084)$. For leukocytes, a significant main effect $\left(\chi_{(11,146)}^{2}=\right.$ 36.62, $p<10^{-3}$ ) was found, which, however, was because of a smaller number of leukocytes at year 9 and 11 as compared with year 4 after implantation $(p<0.024)$. No other pair-wise tests revealed significantly different levels of leukocytes (all $p>0.067$ ). Moreover, with the exception of the mean leukocyte value four years after implantation $(p=0.007)$, no other value differed from baseline before implantation (all $p>0.33$ ).

\section{Effect of controlled fluid supply}

In a typical systems neuroscience experiment, neuronal activity is recorded while monkeys engage in a cognitive task. Task performance is generally based on positive reinforcement protocols (Newsome and Stein-Aviles, 1999; Fischer and Wegener, 2018), using either food or fluid as 
A

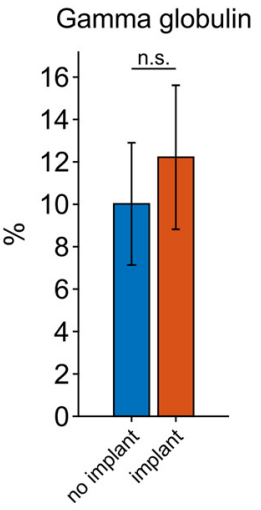

Leukocytes

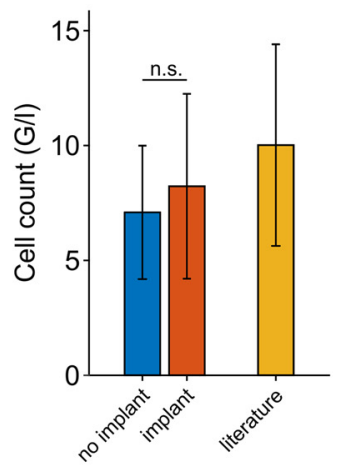

B

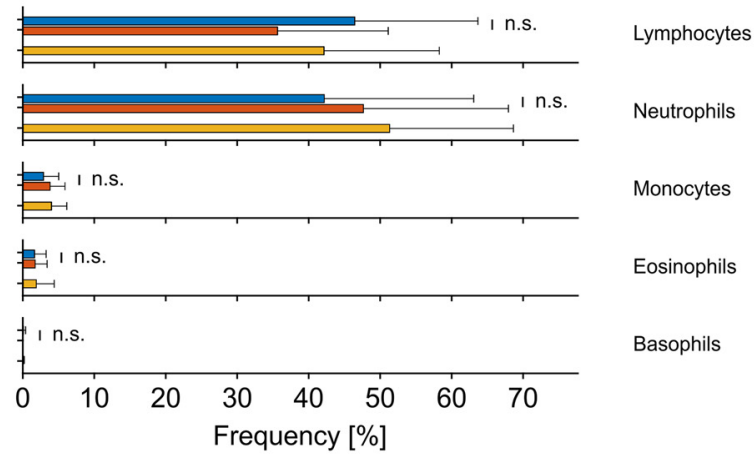

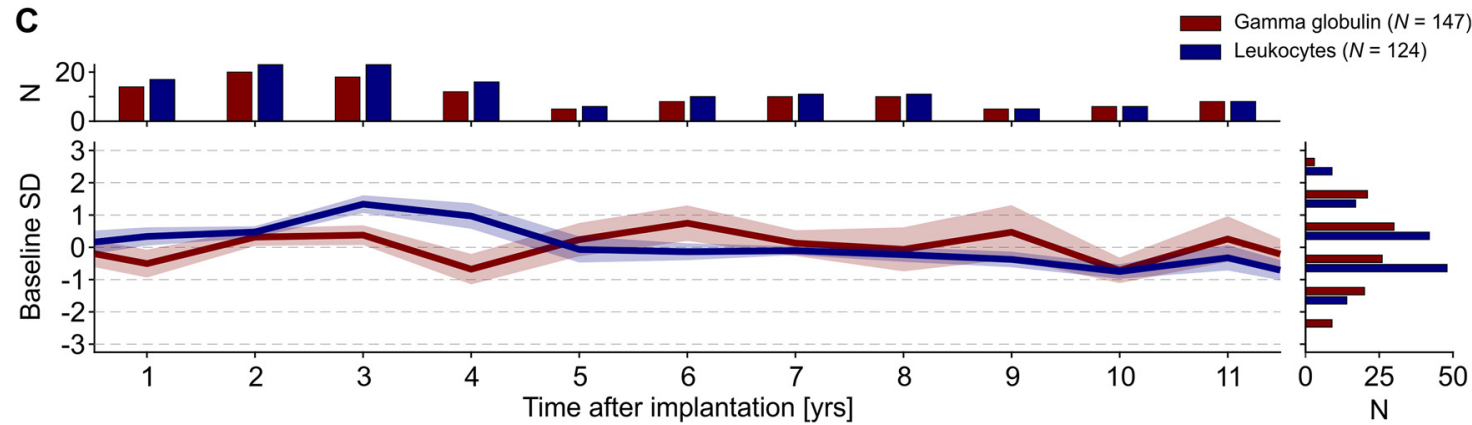

Figure 2. $\gamma$ Globulin and leukocyte levels as markers of chronic inflammatory responses. $\boldsymbol{A}$, Mean $\gamma$ globulin and leukocytes before and 6-18 months after implantation of a head cap, for leukocytes also compared with literature values (compare Fig. 1). Samples before and after implantation were taken from the same animals $(N=11)$. Error bars for own data represent $S D$, error bars for literature values represent the range between the 2.5 th and 97.5 th percentile of published means. G/l: $10^{9}$ cells/L. B, Percentage of the different leukocyte fractions before and after implantation, compared with literature. Error bars as in $\boldsymbol{A}$. $\boldsymbol{C}, \gamma$ globulin and leukocyte levels for up to 11 years after implantation, expressed as mean deviation from overall mean and recalculated to the SD of baseline values before implantation (shown by blue bars in $\boldsymbol{A}$ ). Shading represents SEM; histograms indicate number of individual samples per year (top) and SD (right).

the reinforcer. The choice of the reinforcer mainly depends on the experimental question, but fluid is the reinforcer of choice for the majority of studies. For the effectiveness of the reinforcer, monkeys are usually subjected to well-defined protocols of limited access during periods of laboratory work (lasting up to several weeks or months). Periods of laboratory work may be interrupted by non-laboratory periods ("holidays/vacations"; Prescott et al., 2010), during which monkeys are provided with fluid and food ad libitum.

Fluid protocols mainly differ regarding the amount of fluid provided outside the experimental session (Prescott et al., 2010). In the authors' laboratory, monkeys are allowed to perform the behavioral task until they show no further interest in getting more reward, but they are not provided with additional fluids outside the laboratory. At weekends, during which animals usually do not work, they get individually tailored, generous amounts of fruits and fluids (see Materials and Methods). Besides behavioral observations and laboratory performance, body weight is measured all working days and adds to the information for specifying the individual protocol.

To test whether monkeys regulate their fluid balance appropriately to maintain their health, we analyzed the hematocrit, creatinine, urea, sodium, potassium, and total protein as indicators of kidney function, and serum albumin as indicator of colloid osmotic pressure (Hall, 2015). All parameters were categorized into three groups: (1) "baseline," consisting of samples routinely taken during periods of non-restricted water supply, drawn before any laboratory training; (2) "holidays," consisting of samples routinely taken during non-laboratory periods after at least $10 \mathrm{~d}$ of non-restricted fluid supply; and (3) "laboratory," consisting of samples routinely taken during laboratory periods with limited fluid supply. The database provided between 24 and 68 samples per parameter and group (Fig. $3 A$ ). To avoid a bias from animals with numerous samples, samples of each group were averaged per monkey, resulting in $N=17-26$ values per parameter and group; $p$ values of Kruskal-Wallis tests over the three groups of samples were adjusted to conform to a FDR of $10 \%$. Statistical analysis indicated no effect for hematocrit, creatinine, sodium, potassium, and serum albumin (all $p>0.15)$, but a main effect for urea $(p=0.015)$ and total protein $\left(p<10^{-3}\right)$. Pair-wise tests showed that the urea level of the holidays group was significantly smaller than those of the baseline $(p=0.004)$ and the laboratory $(p=0.014)$ group, while the two latter were not different from each other $(p=0.77)$. For total protein, there was no difference between baseline and holidays $(p=0.27)$, but 
A
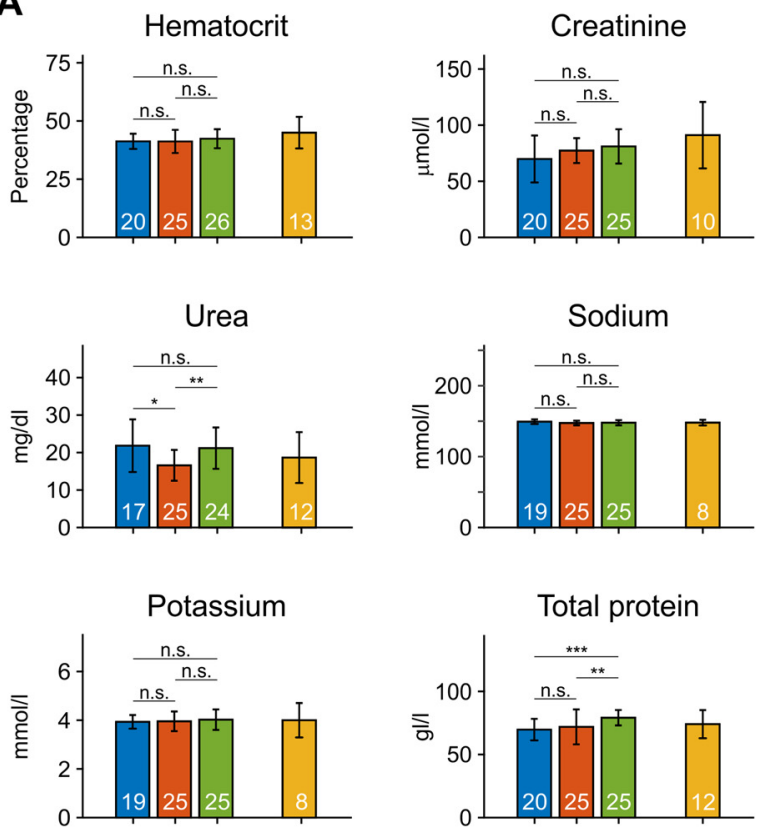

Serum albumin

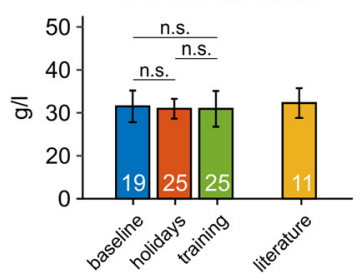

B

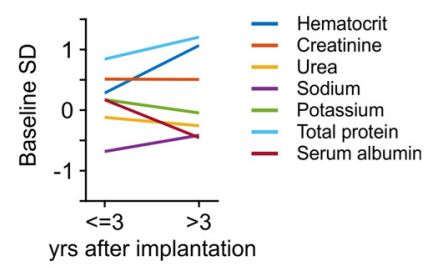

Figure 3. Blood parameters indicative of kidney function and osmolarity during periods of free and limited water supply. $\boldsymbol{A}$, Barplots show mean values of seven key parameters during baseline, holidays, and training, compared with literature values (right-most bars). n.s., not significant; ${ }^{*} p<0.05$, ${ }^{* *} p<0.01$, ${ }^{* \star} p<0.001$. Error bars indicate \pm 1 SD. Numbers in bars provide the $N$ of monkeys contributing to the data or the $N$ of research papers contributing to literature values. $\boldsymbol{B}$, Parameters of the training group, subdivided into early ( $\leq 3$ years after implantation) and late ( $>3$ years after implantation) samples, expressed as fractions of baseline SD.

the laboratory group showed a significantly larger level than the other groups $(p<0.009)$. For all groups and parameters, values were clearly in the physiological range, as obtained from reference data of non-deprived animals (Stanley and Cramer, 1968; Rosenblum and Coulston, 1981; Bennett et al., 1992; Buchl and Howard, 1997; Hom et al., 1999; Smucny et al., 2001; Andrade et al., 2004; Chen et al., 2009; Didier et al., 2012; Koo et al., 2019; Yu et al., 2019).

In addition to comparing between baseline, holiday, and laboratory periods, we further tested whether parameters indicative of hydration may slowly deteriorate over the course of years and subdivided the laboratory group into two temporal groups. The first group consisted of samples drawn during the first three years after implantation and start of laboratory procedures $(N=18$ for all parameters) and the second group consisted of all samples

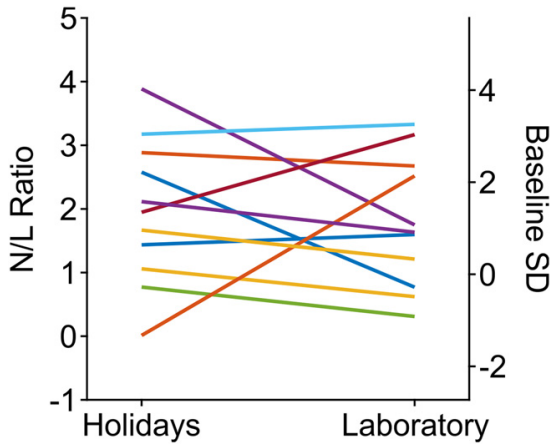

Figure 4. N/L ratio (left $y$-axis) during periods of holidays and laboratory periods of $N=11$ monkeys (colored lines), expressed as fractions of baseline SD (right $y$-axis). Per monkey, baseline, holiday, and laboratory periods are represented by means whenever more than one sample was available.

drawn thereafter $(N=14-16)$. To directly relate these values to the baseline condition before any laboratory work $(N=17-20)$, we subtracted the mean value of the baseline group from the mean values of the two laboratory groups and expressed the difference in terms of baseline SD (Fig. $3 B$ ). For all tested parameters, mean values stayed within $\pm 1 \mathrm{SD}$, independent of the time they were drawn. With the exception of total protein $(Z=2.07, p=0.038, N=[18$ $15]$ ), no other parameter showed a significant difference between samples drawn during the first three years and samples drawn during later years (Wilcoxon rank-sum tests, all $Z<1.9$, all $p>0.1$ ).

\section{Effect of laboratory procedures}

The training of cognitive tasks and the conduction of neurophysiological recordings typically involves temporarily removing an animal from its social group, usage of a primate chair, transport from husbandry to laboratory, restraining by head-fixation, and preparation of recording equipment, as, e.g., mounting a microdrive and lowering down the electrode. These laboratory procedures, together with controlled water or fluid supply, have been discussed to potentially induce distress to the animal in European and United States regulatory and welfare documents (European Parliament, 2010; National Research Council, 2011). However, because the presentation of a complex cognitive task to a distressed animal would have considerable drawbacks when conducting neurophysiological research, an important goal for the refinement of laboratory procedures has been the quantitative assessment of characteristic stress markers. Among those, the level of salivary or plasma cortisol, the primary glucocorticoid in humans and NHPs, has been investigated with respect to social separation, social rank, movement restraint, and fluid deprivation in macaque monkeys (Sapolsky and Mott, 1987; Clarke et al., 1988; Higley et al., 1992; Pfefferle et al., 2018). An alternative to measuring cortisol is to determine the neutrophil/lymphocyte (N/L) ratio in blood samples. Because the biosynthesis of both neutrophils and lymphocytes is modulated by stress hormones (Deitch and Bridges, 
1987), the N/L ratio is suggested as an indirect measure of plasma stress hormone levels and was shown to positively correlate with cortisol (Kim et al., 2005; Lee et al., 2013)

We used the $N / L$ ratio to ask for evidence on increased levels of distress during laboratory periods. Eleven monkeys delivered blood samples during baseline periods before implanting a cranial cap and start of laboratory work, during laboratory periods, and during holiday periods following at least 10 non-laboratory days. Note that monkeys also receive care during holidays, such that they may be taken to the lab for a short time every second or third day. Statistical analysis of this data revealed no significant difference but a trend for differences between the three groups (Kruskal-Wallis test, $\chi_{(2,30)}^{2}=5.45$, $p=0.066$ ). Post hoc analysis showed a tendency for slightly higher $N / L$ ratios during holiday $(p=0.07)$ but not laboratory periods $(p=0.18)$ compared with baseline. A direct comparison between holiday and laboratory periods showed that the $\mathrm{N} / \mathrm{L}$ ratio stayed the same for some individuals, for some others it slightly increased during laboratory periods, and for still some others it slightly decreased (Fig. 4). On the group level, there was no indication for a difference between the two groups $(p=0.9)$.

\section{General health assessment}

Table 2 provides an overview about the entirety of blood values, sorted into three groups: blood values of animals before implantation and start of laboratory procedures (group 1), blood values of animals during the first three years after implantation and start of laboratory procedures (group 2), and blood values of animals at times later than three years after implantation and start of laboratory procedures (group 3). Multiple samples of individual animals were averaged per group, such that each monkey was weighted equally. Per blood value, samples were compared by Kruskal-Wallis tests and, if applicable, paired post hoc tests; $p$ values of Kruskal-Wallis tests were adjusted to conform to an FDR of $10 \%$.

Among 45 blood parameters, three parameters were found to be significantly different. Alkaline phosphatase (AP) of both group 1 and group 2 was higher than of group $3(p<0.01)$, lactate dehydrogenase $(\mathrm{LDH})$ of group 1 was higher than of both group 2 and group 3 $(p<0.001)$, and triglycerides were different between all groups $(p<0.044)$, with group 3 having the highest mean value. AP represents one of seven available liver values, LDH and triglycerides represent two of five muscle values. None of the parameters from the hemogram, differential, and electrophoretic analysis and none of the parameters for kidney and pancreas function was found to deviate significantly between the three groups.

\section{Outer appearance and behavior}

The hematologic analysis of cumulative effects on health and well-being was supplemented by an analysis of the individual score sheets of the monkeys, prepared by an external veterinarian (M.B.). Only monkeys that already participated in laboratory procedures were considered $(N=34)$, to avoid any bias caused by animals that never had participated in laboratory procedures. Individual monkeys were scored between 21 and 122 times, and the overall database provided a total of $N=2375$ score sheets. Each monkey was assessed for five attributes of outer appearance and six attributes of behavior and was scored between 0 and 3 points per attribute, resulting in a total of 33 points possibly given (Table 1). A sum of four points over all 11 attributes marks the lower bound of an overall mildly disturbed healthiness.

In total, 24,913 attributes were scored; 24,704 (99.16\%) of these were without complaint $(-), 193$ were given one point $(+), 14$ were given two points $(++)$, and two were given three points $(+++$; Fig. $5 A)$. Each of the 11 attributes was scored at least twice in the total dataset, and none was scored $>103$ times (Fig. 5B). To investigate whether the frequency of scores, or their overall sum, increased as a function of time after start of laboratory procedures, we plotted the ratio-to-mild $(\mathrm{rtm})$ of all score sheets, aligned to the year of implantation as temporal marker for the start of laboratory work (Fig. 5C). The ratioto-mild equals $r \mathrm{tm}=1$ at the transition from "no complaint" to "mildly disturbed healthiness" and $r \mathrm{tm}=2.5$ at the transition to "moderately disturbed healthiness." The results show that all but four score sheets were below the lower rtm-bound, indicating "no complaint" on overall healthiness. The remaining four score sheets came from three different monkeys and were indicating "mildly disturbed healthiness" (maximal $r t m=1.8$ ) at the time of scoring. No monkey was ever scored as "moderately disturbed."

Regarding the question of cumulative and long-term effects, we found that monkeys were more frequently scored after start of laboratory work $\left(\chi^{2}\right.$ test, $\chi^{2}=23.43$, $p<10^{-5}$ ), but the effect was very small and conformed to a total of 13 scored attributes out of $4835(0.27 \%)$ before implantation and start of laboratory work, and 196 out of $20,078(0.98 \%)$ thereafter, and an increase from mean $\mathrm{rtm}=0.007$ to mean $\mathrm{rtm}=0.028$, respectively. After implantation, there was no increase in rtm over time (linear regression, weighted by number of score sheets per year, $p=0.997$; Fig. 5D).

\section{Discussion}

The present paper investigates the combined, shortterm and long-term influence of typical NHP neuroscientific procedures on hematologic values and general health conditions. The results provide no consistent statistical indication that the presence of a cranial implant, the application of controlled water supply, and exposure to laboratory procedures during training and experimental sessions cause a systematic deviation from baseline and literature levels, and they do not provide evidence of cumulative and long-term effects, or a combination of both. The analysis considered blood sample data taken during a life-span of up to 11 years following cranial implantation and start of laboratory procedures and was complemented by supplementary physiological and behavioral data providing identical conclusions. Albeit absence of statistical evidence is not principally excluding the existence of long-term, cumulative effects, the 
Table 2: Full list of blood parameters over time

\begin{tabular}{|c|c|c|c|c|c|c|c|c|c|c|c|c|c|c|}
\hline Param & Unit & \multicolumn{3}{|c|}{$\begin{array}{c}\text { Group } 1 \\
\text { (baseline) }\end{array}$} & \multicolumn{3}{|c|}{$\begin{array}{c}\text { Group } 2 \\
\text { (implant } \leq 3 \text { years) }\end{array}$} & \multicolumn{3}{|c|}{$\begin{array}{c}\text { Group } 3 \\
\text { (implant }>3 \text { years) }\end{array}$} & $\mathrm{KW}$ & \multicolumn{3}{|c|}{$\begin{array}{c}\text { Paired } \\
\text { tests (groups) }\end{array}$} \\
\hline \multicolumn{15}{|l|}{ Hemogram } \\
\hline Erythrocytes & $\mathrm{T} / \mathrm{I}$ & 5.56 & 0.44 & 19 & 5.54 & 0.41 & 25 & 5.73 & 0.44 & 27 & n.s. & - & - & - \\
\hline Hemoglobin & $g / l$ & 131.71 & 7.49 & 20 & 131.46 & 9.8 & 25 & 135.55 & 12 & 27 & n.s. & - & - & - \\
\hline Hematocrit & $\%$ & 40.86 & 2.81 & 20 & 41.85 & 2.82 & 25 & 42.81 & 3.94 & 27 & n.s. & - & - & - \\
\hline $\mathrm{MCHC}$ & $\mathrm{g} / \mathrm{dl}$ & 32.45 & 1.25 & 19 & 31.83 & 1.04 & 25 & 31.74 & 0.99 & 27 & n.s. & - & - & - \\
\hline Thrombocytes & $\mathrm{G} / \mathrm{l}$ & 369.76 & 76.29 & 19 & 354.43 & 77.13 & 25 & 354.17 & 101.16 & 27 & n.s. & - & - & - \\
\hline \multicolumn{15}{|l|}{ Differential } \\
\hline Basophils & $\%$ & 0.11 & 0.31 & 20 & 0 & 0 & 25 & 0.07 & 0.21 & 27 & n.s. & - & - & - \\
\hline Eosinophils & $\%$ & 1.38 & 1.43 & 20 & 1.65 & 1.34 & 25 & 1.45 & 0.99 & 27 & n.s. & - & - & - \\
\hline Lymphocytes & $\%$ & 45.53 & 18.33 & 20 & 39.61 & 13.69 & 25 & 34.02 & 14.24 & 27 & n.s. & - & - & - \\
\hline \multicolumn{15}{|l|}{ Electrophoresis } \\
\hline Albumin & $g / l$ & 44.7 & 2.86 & 5 & 44.23 & 2.2 & 5 & 44.13 & 4.32 & 17 & n.s. & - & - & - \\
\hline$\alpha 1$-globulin & $g / l$ & 2.67 & 0.41 & 6 & 2.47 & 0.32 & 6 & 2.66 & 0.64 & 17 & n.s. & - & - & - \\
\hline$\alpha 2$-globulin & $g / l$ & 8 & 2 & 6 & 8.94 & 2.46 & 6 & 9.17 & 1.73 & 17 & n.s. & - & - & - \\
\hline$\beta$-globulin & $g / l$ & 7.75 & 2.52 & 6 & 8.62 & 1.89 & 6 & 10.13 & 1.82 & 17 & n.s. & - & - & - \\
\hline$\gamma$-globulin & $g / l$ & 7.58 & 3.64 & 6 & 6.81 & 3.23 & 6 & 10.04 & 2.45 & 17 & n.s. & - & - & - \\
\hline Chloride & $\mathrm{mmol} / \mathrm{l}$ & 108.32 & 1.98 & 17 & 106.6 & 2.9 & 24 & 107.49 & 2.64 & 26 & n.s. & - & - & - \\
\hline Iron & $\mu \mathrm{mol} / \mathrm{l}$ & 25.21 & 6.57 & 19 & 24.04 & 5.75 & 25 & 23.96 & 12.02 & 27 & n.s. & - & - & - \\
\hline \multicolumn{15}{|l|}{ Geriatric profile } \\
\hline $\begin{array}{l}\text { T4 } \\
\text { Kidney }\end{array}$ & $\mu \mathrm{g} / \mathrm{dl}$ & 4.44 & 1.25 & 18 & 4.43 & 1.31 & 24 & 4.87 & 1.28 & 26 & n.s. & - & - & - \\
\hline Urea & mg/dl & 21.97 & 6.89 & 18 & 19.67 & 5.56 & 25 & 18.03 & 5.53 & 26 & n.s. & - & - & - \\
\hline Creatinine & $\mu \mathrm{mol} / \mathrm{l}$ & 69.4 & 17.81 & 20 & 77.69 & 12.65 & 25 & 82.46 & 14.56 & 27 & n.s. & - & - & - \\
\hline$\gamma-\mathrm{GT}$ & $\mathrm{U} / \mathrm{I}$ & 75.47 & 27.08 & 19 & 68.39 & 22.04 & 25 & 60.16 & 23.5 & 27 & n.s. & - & - & - \\
\hline AST & $\mathrm{U} / \mathrm{I}$ & 43.92 & 17.04 & 19 & 38.15 & 24.1 & 25 & 31.17 & 14.2 & 27 & n.s. & - & - & - \\
\hline GLDH & $\mathrm{U} / \mathrm{I}$ & 38.58 & 46.8 & 19 & 20.75 & 13.24 & 25 & 36.7 & 53.69 & 27 & n.s. & - & - & - \\
\hline Serum albumin & $g / l$ & 43.06 & 7.37 & 19 & 44.07 & 4.29 & 25 & 40.22 & 8.02 & 27 & n.s. & - & - & - \\
\hline \multicolumn{15}{|l|}{ Pancreas } \\
\hline Glucose & $\mathrm{mmol} / \mathrm{l}$ & 4.82 & 1.34 & 20 & 4.38 & 1.06 & 25 & 4.66 & 1.34 & 27 & n.s. & - & - & - \\
\hline$\alpha$-Amylase & $\mathrm{U} / \mathrm{I}$ & 468.11 & 105.71 & 19 & 495.52 & 119.96 & 25 & 461.74 & 144.65 & 27 & n.s. & - & - & - \\
\hline Lipase & $\mathrm{U} / \mathrm{I}$ & 22.34 & 6.72 & 18 & 18.55 & 3.47 & 25 & 20.18 & 7.36 & 27 & n.s. & - & - & - \\
\hline Cholesterol & $\mathrm{mmol} / \mathrm{l}$ & 3.57 & 1.06 & 20 & 3.26 & 0.52 & 25 & 3.54 & 0.77 & 27 & n.s. & - & - & - \\
\hline \multicolumn{15}{|l|}{ Muscle } \\
\hline CK & $U / /$ & 174.02 & 74.57 & 19 & 200.53 & 208.21 & 25 & 167.36 & 119.89 & 27 & n.s. & - & - & - \\
\hline $\mathrm{LDH}$ & $\mathrm{U} / \mathrm{I}$ & 402.31 & 146.41 & 19 & 266.37 & 92.61 & 25 & 260.89 & 79.26 & 27 & * & $\star \star \star \star ~$ & 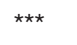 & n.s. \\
\hline Calcium & $\mathrm{mmol} / \mathrm{l}$ & 2.41 & 0.11 & 19 & 2.43 & 0.14 & 25 & 2.47 & 0.14 & 27 & n.s. & - & - & - \\
\hline Magnesium & $\mathrm{mmol} / \mathrm{l}$ & 0.74 & 0.07 & 19 & 0.72 & 0.09 & 25 & 0.78 & 0.08 & 27 & n.s. & - & - & - \\
\hline Triglycerides & $\mathrm{mmol} / \mathrm{l}$ & 0.65 & 1.18 & 19 & 0.63 & 0.38 & 25 & 1.03 & 0.49 & 27 & $\star * \star$ & * & 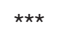 & ** \\
\hline
\end{tabular}

Mean values, SD, and number of samples $N$ are given separately for time periods before implantation and start of laboratory procedures (baseline, group 1 ), during the first three years after implantation and start of laboratory procedures (group 2), and later times (group 3). Column KW provides results of Kruskal-Wallis tests; $p$ values were adjusted to conform to a FDR of $10 \%$. Column paired tests indicates results of post hoc tests when Kruskal-Wallis tests rejected the null hypothesis of equal means. n.s., not significant; ${ }^{*} p<0.05,{ }^{* *} p<0.01,{ }^{* \star *} p<0.001$. U/l, units/l; G/L, $10^{9} \mathrm{U} / \mathrm{l} ; \mathrm{T} / \mathrm{I}, 10^{12} \mathrm{U} / \mathrm{l}$. 
A

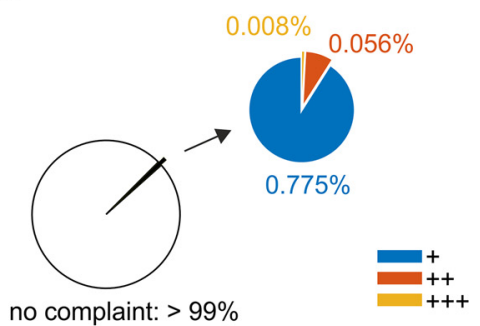

C
B

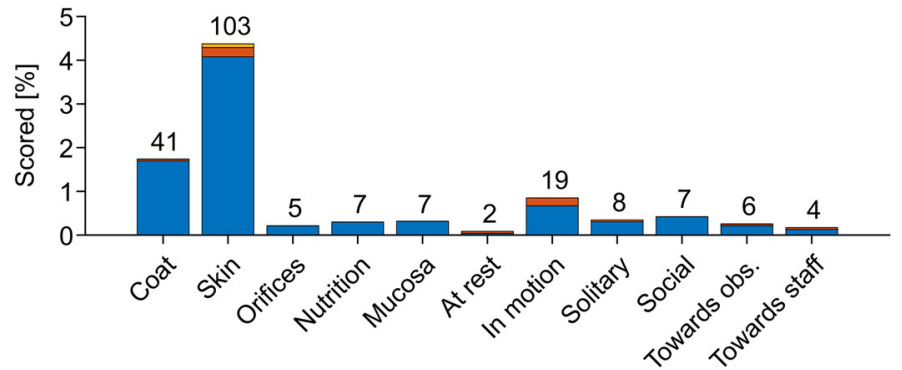

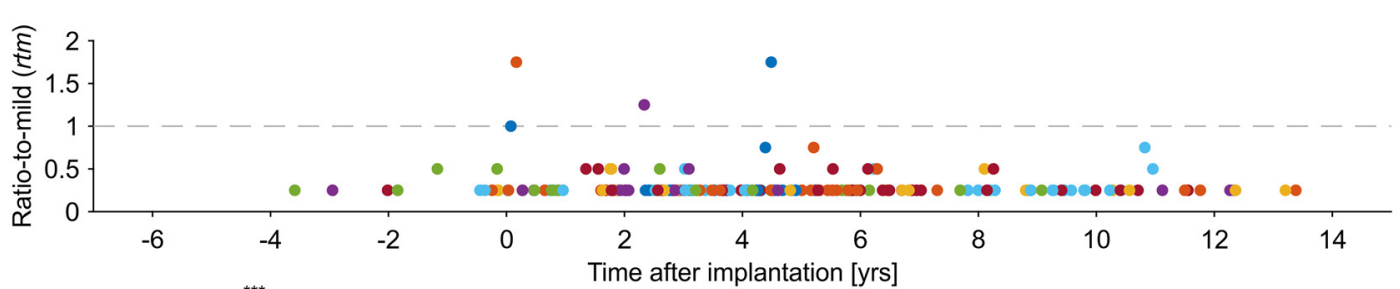

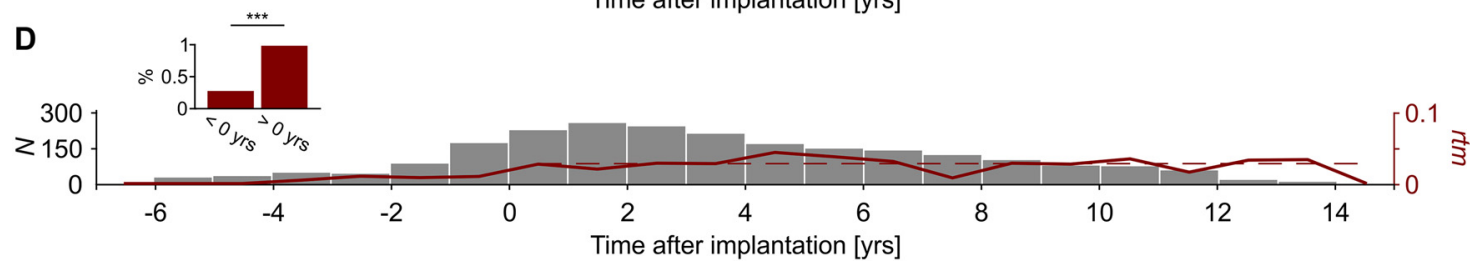

Figure 5. Summary of score sheets. $\boldsymbol{A}$, Score sheets with at least one scored attribute as ratio of all score sheets (lower left) and as ratio of score sheets with one $(+)$ to three $(+++)$ SPs per attribute (upper right). $\boldsymbol{B}$, Ratio of scores for individual attributes. Note that total $N$ was different among attributes (because not always could a monkey been scored regarding all attributes). $\boldsymbol{C}$, Ratio-tomild $\mathrm{rtm}$ for all score sheets with a sum $>0$ points $(N=209)$, aligned to date of implantation. Dashed line indicates transition from "no complaint on healthiness" to "mildly disturbed healthiness" at $r$ tm $=1$. Colors indicate different monkeys. $\boldsymbol{D}$, Total number of score sheets per year, before and after implantation. Red line indicates mean rtm per year (right $y$-axis). Dashed red line indicates weighted linear regression over mean $\mathrm{rtm}$ after implantation and start of laboratory work (slope $<10^{-5}, p=0.997$ ). Inset shows sheets with score sum $>0$ as ratio of total score sheets before and after implantation and start of laboratory procedures; ${ }^{* * *} p<0.001$.

results of the study are in line with a number of recent investigations on potential health effects of NHP experimental procedures, and they underline the effectiveness of the many efforts being taken to optimize them.

\section{Impact of cranial implants}

Cranial implants for mounting headpost and recording chambers were introduced in the early days of neurophysiological studies in the awake, behaving monkey (Evarts, 1968; Wurtz, 1968) and represent, for various reasons, a key technique for the advance of modern neuroscience. For long time, cranial implants typically consisted of a cap of dental acrylic with embedded headpost and recording chamber, anchored by medical screws. Although a generally well compatible technique, a drawback is that granulation tissue sometimes tends to grow at the skin margins of the cap, slowing down postsurgical healing and facilitating the risk of infections. In the worst case, these may become chronic. Refinements of the technique aimed at reducing the risk of infections: several laboratories introduced acrylic-free implants, formed and fabricated based on the individual monkey's cranial anatomy and made from biocompatible materials to support complete osseous-integration (Adams et al., 2007, 2011; McAndrew et al., 2012; Lanz et al., 2013; Johnston et al., 2016; Chen et al., 2017; Overton et al., 2017). Additional refinements were introduced by imaging technologies like magnetic-resonance and computer tomography for, e.g., presurgical planning (Basso et al., 2021), as well as by techniques for postsurgical care as, e.g., the introduction of adaptable implant covers to protect the sutured skin (Perry et al., 2021).

We here add a modification of the surgical procedure for implanting acrylic caps to the list of refinements for cranial implants (see Materials and Methods). We have gained good experience with this technique and obtained cranial implants that show little signs of irritated tissue at the cap margins and require only minimal care over many years. For two key markers of chronic infections, leukocytes and $\gamma$ globulin, our data do not reveal increased levels after implantation of the cranial cap as compared with before. We investigated a postimplantation time span of 11 years and found that leukocyte and $\gamma$ globulin levels always stayed within 2 SDs, mostly within 1 SD, of the baseline distribution obtained before implantation. 
Because small infections at the margins of the cap can never be fully excluded, neither with our implants nor (presumably) with acrylic-free implants, this is suggesting that inflammatory responses, as they may arise occasionally, stay local and do not manifest systemically.

This conclusion is, however, different from the conclusion of two other, recent studies on long-term effects of cranial implants. Frydman et al. (2017) reported lower albumin and calcium concentrations in blood samples of macaques with implants as compared with those without, and also reported higher concentrations of globulin and creatinine. Based on additional investigations, the authors related these effects to the leakage of metal ions from titanium alloy cortical screws used to anchor the cranial implant and/or the recording chamber. Albumin, calcium, globulin and creatinine were found to either correlate with the number of implanted screws or the duration of implantation, or with both. Theil et al. (2021) applied statistical modeling techniques on blood samples of 57 macaques and found that implants were a significant predictor of changes in the number of neutrophils, lymphocytes, and red blood cells, and in the concentrations of hemoglobin, AP, creatinine, calcium, phosphorus, total protein, albumin, and globulin. These results are clearly different from the results of the present study: we found a significant difference between implanted and nonimplanted animals for only three of 45 parameters (AP, LDH, and total protein). We applied a rather liberal FDR of $10 \%$, whereas Theil et al. (2021) used a rather conservative modification of the FDR to account for multiple comparisons. Although our approach increases the expected number of positive test results, it was, nevertheless, much smaller than in Theil et al. (2021). A reason for the discrepancy between these studies and ours might be given by the reduced risk of infection because of the refinement of the surgical procedure, as pointed out earlier. Another reason, however, might be given by more general factors, such as rearing, social experience, housing, enrichment, and stability of social relations; all of which are suggested to have a significant, long-term influence on physiological and immunologic parameters (Capitanio, 1998; Schapiro et al., 2000; BuchananSmith, 2010; Hannibal et al., 2017). The paper of Frydman et al. (2017) does not provide information about housing and social conditions, and the paper of Theil et al. (2021) only mentions that monkeys were kept singly or paired in cages. Monkeys in the authors' institute, however, are housed in established social groups, they have large enclosures equipped with many different objects for climbing, exploring, playing, and have daily access to non-climate controlled outdoor areas, basically fulfilling all requirements of good primate housing as identified by the NC3R Joint Working Group on Refinement (Jennings et al., 2009). We believe that state-of-the-art keeping and housing and versatile social conditions will generally support immune competence and physiological healthiness, and eventually allow monkeys to better cope with the specific experimental situations than under more deprived conditions.

\section{Impact of controlled fluid supply}

Fluid control protocols serve to provide an effective reinforcer during training and performance of cognitive tasks and as a general motivational incentive. Fluid control protocols in NHP laboratories span a relatively wide range, at least partly depending on local legislative regulations (Prescott et al., 2010): at one end, protocols must provide daily ad libitum access to water for a limited period of time on working days and free access to water on non-working days. At the other, fluid access might be limited to laboratory performance on working days and to individually tailored amounts on non-working days. A recent investigation of two different fluid protocols (a moderate and a rather strict one) with a control condition of ad libitum supply indicated only minor differences after 16 weeks of application (Gray et al., 2019). Urine levels of urea and creatinine, and urine specific gravity did not differ between the two fluid control protocols, but the urine was more concentrated than during periods of free access. Blood levels of urea, sodium, and creatinine, and the hematocrit, however, were the same as during free access. Ethograms derived from videotaped material did not provide indication of increased anxiety or other consistent behavioral observations to suggest a decrease in well-being during limited fluid supply, in line with another study (Hage et al., 2014). Both studies concluded that fluid control has less of an impact than often proposed.

In the authors' laboratory, the standard approach is to provide fluid as reward for task performance on working days and individually tailored amounts of fruits and water on the weekend, starting Friday afternoon. Schedules for individual monkeys may include ad libitum supply of water. Schedules are based on task performance on Mondays and body weight: because monkeys are known to work longer and consume more water when they are in low hydration (Yamada et al., 2010; Minamimoto et al., 2012; Gray et al., 2016) and because body weight correlates with hydration (Yamada et al., 2010), below-average uptake of water on Mondays and steady average body weight/week on the long-term supports the conclusion of a well-balanced hydration of the respective individual. The blood values obtained with this protocol support this conclusion. We found that hematocrit, creatinine, urea, sodium, and potassium were not different between baseline and laboratory periods, and we found that all values were well in the range of physiological reference values from non-deprived animals. Urea was slightly lower during holidays, indicating well hydration, and holiday levels of the other parameters were just as during baseline and training. Only for total protein, we found a significant difference between laboratory and baseline/holidays, but absence of a difference between early and late periods following implantation and start of laboratory procedures (compare Table 2). Total protein provides information about the blood levels of albumins and globulins. Abnormal levels could point to dehydration or chronic infection, or a malfunction of kidney or liver. With regard to total proteins, dehydration would be signaled by albumins, which are responsible for $80 \%$ of the colloid osmotic pressure. Yet, albumins neither differed between 
baseline, holidays, and laboratory periods (Fig. 3) nor with regard to time after implantation (Table 2). Chronic infection, in turn, would be signaled by globulins. In neither spectrum did we find an increase of globulins over time (Table 2), especially not for $\gamma$ globulins (Fig. 2). All typical kidney parameters were in the normal range, as were all values for liver, with the exception of AP, which was lower at later times, yet fully in the physiological range (Table 2). Thus, the increase in total protein during training periods is a stand-alone finding that does not coincide with other parameters to indicate dehydration, chronic infection, or a malfunction of liver or kidneys.

The finding that monkeys had adapted well to the fluid schedule is not too surprising given their feeding ecology in natural habitats. Macaques, as many other NHPs, live in arboreal and terrestrial regions, where periods with considerable rainfall may be followed by dry seasons with no water in rivers and ponds, and monthly rainfall of only a few millimeters (Neville, 1968; Lindburg, 1977; Makwana, 1978; Takenaka, 1986). During these times, they are limited to consume water from tree holes and to lick dew and rainwater in the early morning (Sharma et al., 2016). Note that this may coincide with temporary increases of plasma proteins, sodium, and creatinine (Takenaka, 1986). Even in rain season, macaques often refrain from visiting water holes during daytime, or for several days, because of the presence of predators (Lindburg, 1977; Amoroso et al., 2020). Thus, because of the periodic availability of water and for reasons of predator avoidance, macaques, as many other NHP species, have evolved to balance their water intake and maintain their health under conditions of periodical and limited water supply. Laboratory fluid protocols, therefore, are not expected to constitute an unknown physiological challenge, as shown by the absence of detectable changes regarding kidney function, water balance, or general health in our data. Given that (1) task requirements in the laboratory are accessible for the monkey to obtain its desired amount of liquid, (2) behavior and body weight is continuously monitored to allow identification of low hydration, (3) possible deficiencies may be compensated on non-training days, and (4) handling and overall laboratory conditions prevent anxiety and stress, there is also not much reason to assume a priori an impairment in psychological well-being during periods of controlled fluid supply, in line with the behavioral scores we reported here, and the ethograms of previous studies (Hage et al., 2014; Gray et al., 2016).

\section{Impact of laboratory procedures on well-being}

Psychological well-being of laboratory monkeys depends on factors ranging from general housing conditions over enrichment to actual laboratory procedures, including man-monkey interactions at all levels (National Research Council, 1998; Coleman and Novak, 2017). A bunch of literature is available regarding experiences and results for keeping of monkeys in pairs or social groups (Novak and Suomi, 1991; DiVincenti and Wyatt, 2011; Truelove et al., 2017), providing intense sensory, social, and cognitive stimulation (Platt and Novak, 1997; Fagot and Paleressompoulle, 2009; Berger et al., 2018), and using positive reinforcement techniques for voluntary participation in husbandry, veterinary, and research procedures (Prescott and Buchanan-Smith, 2003; Scott et al., 2003; Kemp et al., 2017).

For conducting laboratory procedures, a central goal is to prevent anxiety and minimize distress, for the merit of both the well-being of the animal and the validity of the research data. Distress may occur, however, during initial training of animals: in a recent survey among international NHP laboratories (both governmental/academical and contract research/pharmaceutical sector), about half of all respondents considered some signs of distress during initial training for chair restraint, while only a few laboratories did so for well-trained animals (McMillan et al., 2017). With regard to physiological stress markers, serum cortisol levels during initial chair restraint training were found to be elevated, but were also found to return to baseline after three weeks of training (Lee et al., 2013). Salivary cortisol levels were found to be increased in animals under controlled fluid supply and in implanted animals during care of skin margins, but did not show cumulative effects when caring was applied to animals with controlled fluid access (Pfefferle et al., 2018). Also, the total increase in salivary cortisol was only a fraction of normal daily fluctuations and was thus interpreted as indicating a mild stress response.

We here add data on the long-term effect of laboratory procedures in rhesus macaques. All of the monkeys were implanted and were regularly taken away from their enclosure and their social group to receive care for skin margins and/or perform training or experimental sessions, they were under controlled fluid supply during laboratory periods, and they were subjected to procedures related to data acquisition (e.g., opening the recording chamber, mounting electrode drives, lowering down electrodes, etc.). On the group level, we found that the $N / L$ ratio did not differ between holidays and laboratory periods, and, importantly, also did not differ in comparison to baseline. On the level of individuals, some monkeys showed a slightly increased N/L ratio and some others showed a slightly decreased one, but most had about the same ratio between holidays and laboratory periods. All values were in the physiological range described for humans (Forget et al., 2017), with the exception of two values of the holiday period, one being slightly too high and the other one slightly too low.

In macaque monkeys, the $N / L$ ratio was recently shown to closely correlate with serum cortisol levels and was suggested as an indirect psychophysiological indicator for distress (Kim et al., 2005; Lee et al., 2013), because of the modulation of lymphocyte and neutrophil activity by stress hormones (Deitch and Bridges, 1987). Because it is a response to stress hormones, the $\mathrm{N} / \mathrm{L}$ ratio has a slower time course. Continuous injections of cortisol were shown to significantly increase the level of circulating neutrophils after about $3 \mathrm{~h}$ (Davis et al., 1991). Thus, the N/L ratio is unlikely to be affected by the sampling procedure itself, particularly if animals are trained on it. In rodents, elevated $\mathrm{N} / \mathrm{L}$ ratios were associated with chronic stress exposure (Swan and Hickman, 2014; Hickman, 2017), and in 
monkeys, elevated $\mathrm{N} / \mathrm{L}$ ratios were found during initial chair restrain training (Lee et al., 2013). The finding that in our data there was no difference between holiday and laboratory periods, and also no difference in comparison to baseline does not per se exclude the possibility that laboratory procedures would exert some acute stress. However, the finding does indicate that there is no lasting, cumulative effect, which is expected to show up in a change of the N/L ratio over time. Because the N/L ratio is also modulated by inflammatory responses (Forget et al., 2017), it additionally underlines the results on the absence of chronic inflammatory responses.

In conclusion, the analysis of various blood parameters as indicators for the severity of a variety of typical neuroscientific procedures, and their comparison to baseline parameters obtained before start of any laboratory work, did not provide evidence for cumulative effects resulting from the combination of procedures and it did not provide evidence for cumulative effects over time. Our data indicate that neuroscientific procedures have a much smaller influence on animal well-being and health than often assumed. The procedures and methods we investigated in this report vary only little across most NHP neurophysiology laboratories. Given overall beneficial conditions for the physiological and psychological wellbeing of animals, in terms of social housing in highly enriched environments, positive reinforcement techniques during husbandry, veterinary, and laboratory training, state-of-the-art experimental methods and well-educated staff at all levels, our data suggest that typical procedures required in neuroscience research do not exert a more than mild influence on the health and wellbeing of the animals.

\section{References}

Adams DL, Economides JR, Jocson CM, Horton JC (2007) A biocompatible titanium headpost for stabilizing behaving monkeys. $J$ Neurophysiol 98:993-1001.

Adams DL, Economides JR, Jocson CM, Parker JM, Horton JC (2011) A watertight acrylic-free titanium recording chamber for electrophysiology in behaving monkeys. J Neurophysiol 106:1581-1590.

Amoroso CR, Kappeler PM, Fichtel C, Nunn CL (2020) Temporal patterns of waterhole use as a predator avoidance strategy. $J$ Mammal 101:574-581.

Anderson DM (2008) The nonhuman primate as a model for biomedical research. In: Sourcebook of models for biomedical research (Conn PM, ed), pp 251-258. Totawa: Humana Press.

Andrade MCR, Ribeiro CT, da Silva VF, Molinaro EM, Gonçalves MÂB, Marques MAP, Cabello PH, Leite JPG (2004) Biologic data of Macaca mulatta, Macaca fascicularis, and Saimiri sciureus used for research at the Fiocruz primate center. Mem Inst Oswaldo Cruz 99:584-589.

Basso MA, Frey S, Guerriero KA, Jarraya B, Kastner S, Koyano KW, Leopold DA, Murphy K, Poirier C, Pope W, Silva AC, Tansey G, Uhrig $L$ (2021) Using non-invasive neuroimaging to enhance the care, well-being and experimental outcomes of laboratory nonhuman primates (monkeys). Neuroimage 228:117667.

Benjamini Y, Yekutieli D (2005) False discovery rate-adjusted multiple confidence intervals for selected parameters. J Am Stat Ass 100:71-81.

Bennett JS, Gossett KA, McCarthy MP, Simpson ED (1992) Effects of ketamine hydrochloride on serum biochemical and hematologic variables in rhesus monkeys (Macaca mulatta). Vet Clin Pathol 21:15-18.

Berger M, Calapai A, Stephan V, Niessing M, Burchardt L, Gail A, Treue S (2018) Standardized automated training of rhesus monkeys for neuroscience research in their housing environment. J Neurophysiol 119:796-807.

Bernacky BJ, Gibson SV, Keeling ME, Abee CR (2002) Nonhuman primates. In: Laboratory animal medicine, Ed 2 (Fox JG, Anderson LC, Loew FM, Quimby FW, eds), pp 675-791. Burlington: Academic Press.

Buchanan-Smith HM (2010) Environmental enrichment for primates in laboratories. Adv Sci Res 5:41-56.

Buchl SJ, Howard B (1997) Hematologic and serum biochemical and electrolyte values in clinically normal domestically bred rhesus monkeys (Macaca mulatta) according to age, sex, and gravidity. Lab Anim Sci 47:528-533.

Capitanio JP (1998) Social experience and immune system measures in laboratory-housed macaques: implications for management and research. ILAR J 39:12-20.

Castiello U, Dadda M (2019) A review and consideration on the kinematics of reach-to-grasp movements in macaque monkeys. $J$ Neurophysiol 121:188-204.

Chandrashekar A, Liu J, Martinot AJ, McMahan K, Mercado NB, Peter L, Tostanoski LH, Yu J, Maliga Z, Nekorchuk M, BusmanSahay K, Terry M, Wrijil LM, Ducat S, Martinez DR, Atyeo C, Fischinger S, Burke JS, Slein MD, Pessaint L, et al. (2020) SARSCoV-2 infection protects against rechallenge in rhesus macaques. Science 369:812-817.

Chen X, Possel JK, Wacongne C, van Ham AF, Klink PC, Roelfsema PR (2017) 3D printing and modelling of customized implants and surgical guides for non-human primates. J Neurosci Methods 286:38-55.

Chen Y, Qin S, Ding Y, Wei L, Zhang J, Li H, Bu H, Lu Y, Cheng J (2009) Reference values of clinical chemistry and hematology parameters in rhesus monkeys (Macaca mulatta). Xenotransplantation 16:496-501.

Clarke AS, Mason WA, Moberg GP (1988) Differential behavioral and adrenocortical responses to stress among three macaque species. Am J Primatol 14:37-52.

Coleman K, Novak MA (2017) Environmental enrichment in the 21st century. ILAR J 58:295-307.

Corbett KS, Flynn B, Foulds KE, Francica JR, Boyoglu-Barnum S, Werner AP, Flach B, O'Connell S, Bock KW, Minai M, Nagata BM, Andersen H, Martinez DR, Noe AT, Douek N, Donaldson MM, Nji NN, Alvarado GS, Edwards DK, Flebbe DR, et al. (2020) Evaluation of the mRNA-1273 vaccine against SARS-CoV-2 in nonhuman primates. N Engl J Med 383:1544-1555.

Davis JM, Albert JD, Tracy KJ, Calvano SE, Lowry SF, Shires GT, Yurt RW (1991) Increased neutrophil mobilization and decreased chemotaxis during cortisol and epinephrine injections. J Trauma 31:725-732.

Deaner RO, Platt ML (2003) Reflexive social attention in monkeys and humans. Curr Biol 13:1609-1613.

Deitch EA, Bridges RM (1987) Stress hormones modulate neutrophil and lymphocyte activity in vitro. J Trauma 27:1146-1154.

Deng W, Bao L, Liu J, Xiao C, Liu J, Xue J, Lv Q, Qi F, Gao H, Yu P, Xu Y, Qu Y, Li F, Xiang Z, Yu H, Gong S, Liu M, Wang G, Wang S, Song Z, et al. (2020) Primary exposure to SARS-CoV-2 protects against reinfection in rhesus macaques. Science 369:818-823.

Didier ES, Sugimoto C, Bowers LC, Khan IA, Kuroda MJ (2012) Immune correlates of aging in outdoor-housed captive rhesus macaques (Macaca mulatta). Immun Ageing 9:25.

DiVincenti L Jr, Wyatt JD (2011) Pair housing of macaques in research facilities: a science-based review of benefits and risks. $J$ Am Assoc Lab Anim Sci 50:856-863.

European Parliament (2010) Directive 2010/63 of the European Parliament and of the Council of 22 September 2010 on the protection of animals used for scientific research. Available at http://data.europa.eu/eli/dir/2010/63/2019-06-26.

Evans DT, Silvestri G (2013) Nonhuman primate models in AIDS research. Curr Opin HIV AIDS 8:255-261. 
Evarts EV (1968) Relation of pyramidal tract activity to force exerted during voluntary movement. J Neurophysiol 31:14-27.

Fagot J, Paleressompoulle D (2009) Automatic testing of cognitive performance in baboons maintained in social groups. Behav Res Methods 41:396-404.

Fernie S, Wrenshall E, Malcolm S, Bryce F, Arnold DL (1994) Normative hematologic and serum biochemical values for adult and infant rhesus monkeys (Macaca mulatta) in a controlled laboratory environment. J Toxicol Environ Health 42:53-72.

Fischer B, Wegener D (2018) Emphasizing the 'positive' in positive reinforcement: using non-binary rewarding for training monkeys on cognitive tasks. J Neurophysiol 120:115-128.

Forget P, Khalifa C, Defour JP, Latinne D, Van Pel MC, De Kock M (2017) What is the normal value of the neutrophil-to-lymphocyte ratio? BMC Res Notes 10:12.

Fries $\mathrm{P}$ (2015) Rhythms for cognition: communication through coherence. Neuron 88:220-235.

Frydman GH, Marini RP, Bakthavatchalu V, Biddle KE, Muthupalani S, Vanderburg CR, Lai B, Bendapudi PK, Tompkins RG, Fox JG (2017) Local and systemic changes associated with long-term, percutaneous, static implantation of titanium alloys in rhesus macaques (Macaca mulatta). Comp Med 67:165-175.

Galashan FO, Rempel HC, Meyer A, Gruber-Dujardin E, Kreiter AK, Wegener D (2011) A new type of recording chamber with an easyto-exchange microdrive array for chronic recordings in macaque monkeys. J Neurophysiol 105:3092-3105.

Gardiner TW, Toth LA (1999) Stereotactic surgery and long-term maintenance of cranial implants in research animals. Contemp Top Lab Anim Sci 38:56-63.

Gardner MB, Luciw PA (2008) Macaque models of human infectious disease. ILAR J 49:220-255.

Gray DT, Barnes CA (2019) Experiments in macaque monkeys provide critical insights into age-associated changes in cognitive and sensory function. Proc Natl Acad Sci USA 116:26247-26254.

Gray H, Bertrand H, Mindus C, Flecknell P, Rowe C, Thiele A (2016) Physiological, behavioral, and scientific impact of different fluid control protocols in the rhesus macaque (Macaca mulatta). eNeuro 3:ENEURO.0195-16.2016.

Gray H, Thiele A, Rowe C (2019) Using preferred fluids and different reward schedules to motivate rhesus macaques (Macaca mulatta) in cognitive tasks. Lab Anim 53:372-382.

Grothe I, Neitzel SD, Mandon S, Kreiter AK (2012) Switching neuronal inputs by differential modulation of gamma-band phase-coherence. J Neurosci 32:16172-16180.

Hage SR, Ott T, Eiselt AK, Jacob SN, Nieder A (2014) Ethograms indicate stable well-being during prolonged training phases in rhesus monkeys used in neurophysiological research. Lab Anim 48:82-87.

Hall JE (2015) Guyton and Hall textbook of medical physiology, Ed 13. London: W.B. Saunders.

Hanks TD, Summerfield C (2017) Perceptual decision making in rodents, monkeys, and humans. Neuron 93:15-31.

Hannibal DL, Bliss-Moreau E, Vandeleest J, McCowan B, Capitanio $J$ (2017) Laboratory rhesus macaque social housing and social changes: implications for research. Am J Primatol 79:1-14.

Hickman DL (2017) Evaluation of the neutrophil:lymphocyte ratio as an indicator of chronic distress in the laboratory mouse. Lab Anim (NY) 46:303-307.

Higley JD, Suomi SJ, Linnoila M (1992) A longitudinal assessment of CSF monoamine metabolite and plasma cortisol concentrations in young rhesus monkeys. Biol Psychiatry 32:127-145.

Hom GJ, Bach TJ, Carroll D, Forrest MJ, Mariano MA, Trainor CE, Wang PR, Macintyre DE (1999) Comparison of cardiovascular parameters and/or serum chemistry and hematology profiles in conscious and anesthetized rhesus monkeys (Macaca mulatta). Contemp Top Lab Anim Sci 38:60-64.

Hosokawa T, Watanabe M (2012) Prefrontal neurons represent winning and losing during competitive video shooting games between monkeys. J Neurosci 32:7662-7671.
Jennings M, Prescott MJ, Buchanan-Smith HM, Gamble MR, Gore M, Hawkins $P$, Hubrecht R, Hudson S, Jennings M, Keeley JR, Morris K, Morton DB, Owen S, Pearce PC, Prescott MJ, Robb D, Rumble RJ, Wolfensohn S, Buist D; Members of the Joint Working Group on Refinement (Primates) (2009) Refinements in husbandry, care and common procedures for non-human primates: ninth report of the BVAAWF/FRAME/RSPCA/UFAW Joint Working Group on Refinement. Lab Anim 43 [Suppl 1]:1-47.

Johnston JM, Cohen YE, Shirley H, Tsunada J, Bennur S, ChristisonLagay K, Veeder CL (2016) Recent refinements to cranial implants for rhesus macaques (Macaca mulatta). Lab Anim (NY) 45:180186.

Kastner S, De Weerd P, Ungerleider LG (2008) Cortical mechanisms of visuospatial attention in humans and monkeys. In: Topics in integrative neuroscience: from cells to cognition (Pomerantz JR, ed), pp 77-118. Cambridge: Cambridge University Press.

Kessler MJ, Rawlins RG (1983) The hemogram, serum biochemistry, and electrolyte profile of the free-ranging Cayo Santiago rhesus macaques (Macaca mulatta). Am J Primatol 4:107-116.

Kemp C, Thatcher H, Farningham D, Witham C, MacLarnon A, Holmes A, Semple S, Bethell EJ (2017) A protocol for training group-housed rhesus macaques (Macaca mulatta) to cooperate with husbandry and research procedures using positive reinforcement. Appl Anim Behav Sci 197:90-100.

Kim CY, Han JS, Suzuki T, Han SS (2005) Indirect indicator of transport stress in hematological values in newly acquired cynomolgus monkeys. J Med Primatol 34:188-192.

Koo BS, Lee DH, Kang P, Jeong KJ, Lee S, Kim K, Lee Y, Huh JW, Kim YH, Park SJ, Jin YB, Kim SU, Kim JS, Son Y, Lee SR (2019) Reference values of hematological and biochemical parameters in young-adult cynomolgus monkey (Macaca fascicularis) and rhesus monkey (Macaca mulatta) anesthetized with ketamine hydrochloride. Lab Anim Res 35:7-6.

Kreiter AK (2020) Synchrony, flexible network configuration, and linking neural events to behavior. Curr Opin Physiol 16:98-108.

Lanz F, Lanz X, Scherly A, Moret V, Gaillard A, Gruner P, Hoogewoud HM, Belhaj-Saif A, Loquet G, Rouiller EM (2013) Refined methodology for implantation of a head fixation device and chronic recording chambers in non-human primates. J Neurosci Methods 219:262-270.

Lee JI, Shin JS, Lee JE, Jung WY, Lee G, Kim MS, Park CG, Kim SJ (2013) Changes of N/L ratio and cortisol levels associated with experimental training in untrained rhesus macaques. J Med Primatol 42:10-14

Lindburg DG (1977) Feeding behaviour and diet of rhesus monkeys (Macaca mulatta) in a Siwalik forest in north India. In: Primate ecology: studies of feeding and ranging behaviour in lemurs, monkeys and apes (Clutton-Brock TH, ed), pp 223-249. London: Academic Press.

Makwana SC (1978) Field ecology and behaviour of the rhesus macaque (Macaca mulatta): I. Group composition, home range, roosting sites, and foraging routes in the Asarori Forest. Primates 19:483-492.

Martin P, Leibovich SJ (2005) Inflammatory cells during wound repair: the good, the bad and the ugly. Trends Cell Biol 15:599-607.

McAndrew RM, Lingo VanGilder JL, Naufel SN, Helms Tillery SI (2012) Individualized recording chambers for non-human primate neurophysiology. J Neurosci Methods 207:86-90.

McMillan JL, Bloomsmith MA, Prescott MJ (2017) An international survey of approaches to chair restraint of nonhuman primates. Comp Med 67:442-451.

Mercado NB, Zahn R, Wegmann F, Loos C, Chandrashekar A, Yu J, Liu J, Peter L, McMahan K, Tostanoski LH, He X, Martinez DR, Rutten L, Bos R, van Manen D, Vellinga J, Custers J, Langedijk JP, Kwaks T, Bakkers MJG, et al. (2020) Single-shot Ad26 vaccine protects against SARS-CoV-2 in rhesus macaques. Nature 586:583-588.

Minamimoto T, Yamada H, Hori Y, Suhara T (2012) Hydration level is an internal variable for computing motivation to obtain water rewards in monkeys. Exp Brain Res 218:609-618. 
Munoz DP, Everling S (2004) Look away: the anti-saccade task and the voluntary control of eye movement. Nat Rev Neurosci 5:218228.

Munster VJ, Feldmann F, Williamson BN, van Doremalen N, PérezPérez L, Schulz J, Meade-White K, Okumura A, Callison J, Brumbaugh B, Avanzato VA, Rosenke R, Hanley PW, Saturday G, Scott D, Fischer ER, de Wit E (2020) Respiratory disease in rhesus macaques inoculated with SARS-CoV-2. Nature 585:268-272.

National Research Council (1998) The psychological well-being of nonhuman primates. Washington, DC: National Academy Press.

National Research Council (2011) Guide for the care and use of laboratory animals, Ed 8. Washington, DC: National Academy Press.

Neville MK (1968) Ecology and activity of Himalayan foothill rhesus monkeys (Macaca mulatta). Ecology 49:110-123.

Newsome WT, Stein-Aviles JA (1999) Nonhuman primate models of visually based cognition. ILAR J 39:78-91.

Novak MA, Suomi SJ (1991) Social interaction in nonhuman primates: an underlying theme for primate research. Lab Anim Sci 41:308-314.

Orban GA, Van Essen D, Vanduffel W (2004) Comparative mapping of higher visual areas in monkeys and humans. Trends Cogn Sci 8:315-324.

Overton JA, Cooke DF, Goldring AB, Lucero SA, Weatherford C, Recanzone GH (2017) Improved methods for acrylic-free implants in nonhuman primates for neuroscience research. J Neurophysiol 118:3252-3270.

Perry BAL, Mason S, Nacef J, Waddle A, Hynes B, Bergmann C, Schmid MC, Petkov CI, Thiele A, Mitchell AS (2021) Protective cranial implant caps for macaques. J Neurosci Methods 348:108992.

Petrides M, Tomaiuolo F, Yeterian EH, Pandya DN (2012) The prefrontal cortex: comparative architectonic organization in the human and the macaque monkey brains. Cortex 48:4657.

Pfefferle D, Plümer S, Burchardt L, Treue S, Gail A (2018) Assessment of stress responses in rhesus macaques (Macaca mulatta) to daily routine procedures in system neuroscience based on salivary cortisol concentrations. PLoS One 13:e0190190.

Platt DM, Novak MA (1997) Videostimulation as enrichment for captive rhesus monkeys (Macaca mulatta). Appl Anim Behav Sci 52:139-155.

Prescott MJ, Buchanan-Smith HM (2003) Training nonhuman primates using positive reinforcement techniques. J Appl Anim Welf Sci 6:157-161.

Prescott MJ, Brown VJ, Flecknell PA, Gaffan D, Garrod K, Lemon RN, Parker AJ, Ryder K, Schultz W, Scott L, Watson J, Whitfield L (2010) Refinement of the use of food and fluid control as motivational tools for macaques used in behavioural neuroscience research: report of a working group of the NC3Rs. J Neurosci Methods 193:167-188.

Rajalingham R, Schmidt K, DiCarlo JJ (2015) Comparison of object recognition behavior in human and monkey. J Neurosci 35:1212712136.

Rauschecker J, Scott S (2009) Maps and streams in the auditory cortex: nonhuman primates illuminate human speech processing. Nat Neurosci 12:718-724.

Rizzolatti G, Craighero L (2004) The mirror neuron system. Annu Rev Neurosci 27:169-192.

Rizzolatti G, Rozzi S (2016) Motor cortex and mirror system in monkeys and humans. In: Neurobiology of language (Hickok G, Small SL, eds), pp 59-72. San Diego: Academic Press.

Roberts AC, Clarke HF (2019) Why we need nonhuman primates to study the role of ventromedial prefrontal cortex in the regulation of threat- and reward-elicited responses. Proc Natl Acad Sci USA 116:26297-26304.

Roelfsema PR, Treue S (2014) Basic neuroscience research with nonhuman primates: a small but indispensable component of biomedical research. Neuron 82:1200-1204.
Rosenblum IY, Coulston F (1981) Normal range and longitudinal blood chemistry and hematology valves in juvenile and adult rheusus monkeys (Macaca mulatta). Ecotoxicol Environ Saf 5:401-411.

Sapolsky RM, Mott GE (1987) Social subordinance in wild baboons is associated with suppressed high density lipoproteincholesterol concentrations: the possible role of chronic social stress. Endocrinology 121:1605-1610.

Schapiro SJ, Nehete PN, Perlman JE, Sastry KJ (2000) A comparison of cell-mediated immune responses in rhesus macaques housed singly, in pairs, or in groups. Appl Anim Behav Sci 68:67-84

Schledde B, Galashan FO, Przybyla M, Kreiter AK, Wegener D (2017) Task-specific, dimension-based attentional shaping of motion processing in monkey area MT. J Neurophysiol 118:1542-1555.

Schroeder HW Jr, Cavacini L (2010) Structure and function of immunoglobulins. J Allergy Clin Immunol 125:S41-S52.

Scott L, Pearce P, Fairhall S, Muggleton N, Smith J (2003) Training nonhuman primates to cooperate with scientific procedures in applied biomedical research. J Appl Anim Welf Sci 6:199-207.

Sharma N, Huffman MA, Gupta S, Nautiyal H, Mendonça R, Morino L, Sinha A (2016) Watering holes: the use of arboreal sources of drinking water by Old World monkeys and apes. Behav Processes 129:18-26.

Siegel M, Donner TH, Engel AK (2012) Spectral fingerprints of large-scale neuronal interactions. Nat Rev Neurosci 13:121134.

Smucny DA, Allison DB, Ingram DK, Roth GS, Kemnitz JW, Kohama SG, Lane MA; Primate Aging Database Working Group (2001) Changes in blood chemistry and hematology variables during aging in captive rhesus macaques (Macaca mulatta). J Med Primatol 30:161-173.

Stanley RE, Cramer MB (1968) Hematologic values of the monkey (Macaca mulatta). Am J Vet Res 29:1041-1047.

Swan MP, Hickman DL (2014) Evaluation of the neutrophil-lymphocyte ratio as a measure of distress in rats. Lab Anim (NY) 43:276282.

Takenaka O (1986) Blood characteristics of the crab-eating monkeys (Macaca fascicularis) in Bali Island, Indonesia: implication of water deficiency in West Bali. J Med Primatol 15:97-104.

Theil JH, Johns JL, Chen P, Theil DM, Albertelli MA (2021) Hematology and culture assessment of cranially implanted rhesus macaques (Macaca mulatta). Comp Med 71:166-176.

Thiebaut de Schotten M, Dell'Acqua F, Valabregue R, Catani M (2012) Monkey to human comparative anatomy of the frontal lobe association tracts. Cortex 48:82-96.

Tokuno H, Watson C, Roberts A, Sasaki E, Okano H (2015) Marmoset neuroscience. Neurosci Res 93:1-2.

Truelove MA, Martin AL, Perlman JE, Wood JS, Bloomsmith MA (2017) Pair housing of macaques: a review of partner selection, introduction techniques, monitoring for compatibility, and methods for long-term maintenance of pairs. Am J Primatol 79:1-15.

Uhlhaas PJ, Singer W (2006) Neural synchrony in brain disorders: relevance for cognitive dysfunctions and pathophysiology. Neuron 52:155-168.

van Doremalen N, Lambe T, Spencer A, Belij-Rammerstorfer S, Purushotham JN, Port JR, Avanzato VA, Bushmaker T, Flaxman A, Ulaszewska M, Feldmann F, Allen ER, Sharpe H, Schulz J, Holbrook M, Okumura A, Meade-White K, Pérez-Pérez L, Edwards NJ, Wright D, et al. (2020) ChAdOx1 nCoV-19 vaccine prevents SARS-CoV-2 pneumonia in rhesus macaques. Nature 586:578582.

Verdier J-M, Acquatella I, Lautier C, Devau G, Trouche S, Lasbleiz C, Mestre-Francés N (2015) Lessons from the analysis of nonhuman primates for understanding human aging and neurodegenerative diseases. Front Neurosci 9:64.

Vogel AB, Kanevsky I, Che Y, Swanson KA, Muik A, Vormehr M, Kranz LM, Walzer KC, Hein S, Güler A, Loschko J, Maddur MS, 
Ota-Setlik A, Tompkins K, Cole J, Lui BG, Ziegenhals T, Plaschke A, Eisel D, Dany SC, et al. (2021) BNT162b vaccines protect rhesus macaques from SARS-CoV-2. Nature 592:283-289.

Wegener D, Freiwald WA, Kreiter AK (2004) The influence of sustained selective attention on stimulus selectivity in macaque visual area MT. J Neurosci 24:6106-6114.

Wurtz RH (1968) Visual cortex neurons: response to stimuli during rapid eye movements. Science 162:1148-1150.
Yamada H, Louie K, Glimcher PW (2010) Controlled water intake: a method for objectively evaluating thirst and hydration state in monkeys by the measurement of blood osmolality. J Neurosci Methods 191:83-89.

Yu W, Hao X, Yang F, Ma J, Zhao Y, Li Y, Wang J, Xu H, Chen L, Liu Q, Duan S, Yang Y, Huang F, He Z (2019) Hematological and biochemical parameters for Chinese rhesus macaque. PLoS One 14: e0222338. 